\title{
PENDAMPINGAN DAN PEMBERDAYAAN PENGELOLAAN KEUANGAN PADA LPD DESA ADAT CEPAKA
}

\author{
I Ketut Yudana Adi ${ }^{*}$, Kukuh Rian Setiawan², Ida Ketut Kusumawijaya ${ }^{3}$ \\ (Universitas Triatma Mulya ${ }^{1,2,3}$ ) \\ yudana.adi@triatmamulya.ac.id ${ }^{*}$
}

\begin{abstract}
Covid 19 pandemic has a huge impact on the Cepaka Village Community, starting from the closure of the tourism sector for foreign tourists, SMEs with low orders, culinary selling products with a low cost strategy, jogging tracks and bicycle tracking which are crowded with domestic tourists, cannot provide economic benefits, so does not give value to farmers who own rice fields that are traversed by cycling tourists or tourists who jog and take selfies as well as the financial behavior of rural communities that tends to be consumptive, causing the Cepaka Village community to not be economically prosperous. The focus of this activity is carried out based on this grouping, namely Creating, packaging / packaging tourism villages by involving all existing potentials, and involving the village community. Management / governance of UKM and services that will be the core products of tourism villages and the impact of tourism villages, and Carry out assistance activities for community financial institutions in cooperatives, LPDs, traditional markets, waste banks and BUMDES of Cepaka Village.
\end{abstract}

Keywords: financial management.

\section{PENDAHULUAN}

LPD merupakan salah satu unsur kelembagaan Desa Adat yang menjalankan fungsi keuangan desa adat untuk mengelola potensi keuangan Desa Adat. Lembaga ini sangat berpotensi dan telah terbukti dalam memajukan kesejahteraan masyarakat desa dan memenuhi kepentingan Desa Adat itu sendiri. LPD sebagai salah satu wadah kekayaan Desa Adat, menjalankan fungsinya dalam bentuk usaha-usaha kearah peningkatan taraf hidup krama Desa Adat dan dalam kegiatannya banyak menunjang pembangunan Desa Adat.

LPD Desa Desa Adat Cepaka yang ada di Kecamatan Kediri, Kabupaten Tabanan yang berdiri tahun 1992, dikelola oleh 3 orang
Pengurus. Tingkat pendidikan Pengurus tertinggi sampai Pendidikan S1, LPD yang beroperasi di sekitar Desa Adat Cepaka, desa ini merupakan salah satu wilayah di daerah penyanggah pembangunan dan daerah Pariwisata cukup srategis. Daerah ini dekat dengan pusat pemerintahan, lembaga pendidikan dan pusat bisnis di Kabupaten Badung.

LPD Desa Adat Cepaka merupakan Lembaga Keuangan Desa yang sedang berkembang dan masih dalam fase pemulihan setelah mengalami keterpurukan dari sisi finansial dan manajemen. Perlu dukungan dari seluruh komponen masyarakat agar pembangunan di Desa Adat Cepaka bisa terlaksana 
dengan baik. Karena $20 \%$ dari sisa hasil usaha (Laba) LPD setiap tahunnya adalah untuk pembangunan Desa Adat. LPD Desa adat Cepakayang berlokasi di Jalan Cepaka No.68, Banjar Lalang Pasek, Desa Cepaka, Kecamatan Kediri, Kabupaten Tabanan sudah melayani warga Desa Adat yang menjadi nasabah tabungan sebanyak 466 orang dan nasabah peminjam sebanyak 114 orang.

Misi Desa Cepaka dibidang pembangunan salah satunya yaitu meningkatkan ketahanan ekonomi dengan menggalakkan usaha ekonomi kerakyatan, melalui program strategis di bidang produksi pertanian, pemasaran ,Usaha kecil dan menengah (UMKM) serta Koperasi dan LPD (Lembaga Perkreditan Desa).

Untuk mewujudkan Misi tersebut sangat dibutuhkan peranan khusunya Lembaga Keuangan seperti koperasi dan LPD dalam mendukung pembiayaan atau modal usaha untuk usaha kecil dan menengah serta sektor pertanian dan pendukung pariwisata. Tetapi tanpa dukungan dari masyarakatnya untuk memanfaatkan lembaga keuangan seperti LPD, semua itu akan tidak berjalan sesuai harapan dari Misi tersebut. Dibutuhkan kesadaran dari masyarakat untuk ikut memajukan LPD untuk tujuan ketahanan Ekonomi Kerakyatan.

Pandemi Covid 19, membuat aktivitas desa ini menjadi tertutup dan berdampak pada semua sektor di Desa Cepaka. Pada LPD Desa Adat Cepaka sangat dirasakan untuk transaski yang terjadi selama pandemi covid-19 sangat menurun.
LPD yang bertumpu pada kegiatan dan usaha masyarakat adat perlu strategi dalam pemasaran dan pengelolaan keuangan yang baik sehingga mampu memberikan benefit yang berimbang.

Dari data tersebut bisa disimpulkan terdapat beberapa permasalahan yang terjadi, antara lain:

a. Proses pencatatan transaksi secara konvensional dapat menimbulkan risiko, Penutupan sector pariwisata bagi wisatawan asing berdampak pada pekerja pariwisata yang tidak mampu membiayai kehidupan keluarga sehingga kehidupan ekonomi dan social mereka juga terganggu.

b. UKM-UKM sepi orderan, sanggar tari yang biasa pentas tidak ada kegiatan, kuliner menjual produk dengan strategi low cost.

c. Jalur jogging dan tracking sepeda yang ramai dikunjungi oleh wisatawan domestic, tidak bisa member manfaat ekonomi, sehingga tidak member value kepada para petani pemilik sawah yang dilalui oleh wisatawan bersepeda maupun wisatawan yang jogging dan berswa-foto.

d. Belum ada pengkemasan produk dan potensi Desa Cepaka menjadi desa wisata yang utuh dan melibatkan seluruh masyarakat yang mencakup aspek hukum, sumber daya, layanan, pemberdayaan UKMUKM dan penyediaan akomodasi.

e. Perilaku keuangan masyarakat desa yang masih cenderung 
konsumtif dan terbiasa berhutang kepada rentenir, sehingga masyarakat tidak sejahtera secara ekonomi.

Desa Cepaka sebagai desa mitra Universitas Triatma Mulya memiliki banyak potensi wisata, namun keterbatasan ilmu pengetahuan mereka tentang pembukuan menjadi kendala dalam keuangan desa wisata tersebut. Kompetensi yang dibutuhkan oleh Desa Cepaka dimiliki oleh dosen dan mahasiswa secara utuh, sehingga implementasi program PKM ini berpotensi dapat dilaksanakan secara optimal.

Berdasarkan permasalahan yang terjadi, maka tujuan program PKM adalah sebagai berikut:

1. Membuat Kelompok Sadar Wisata (POKDARWIS) sebagai lembaga terendah yang memiliki hak untuk mengelola desa wisata agar bermanfaat secara ekonomi.

2. Penggalian potensi wisata yakni dengan cara: pembuatan jalur / lintasan wisata sepeda dan jogging track yang menarik dan terkontrol dengan pemasangan "caring donation box"

3. Pemberdayaan masyarakat untuk membuat spot foto, spot layanan makan dan minum, spot mincing atau spot melihat tanaman sehingga spot-spot ini berpotensi secara ekonomi bagi masyarakat desa.

4. Menggeser aktifitas UKM kepada aktivitas yang mendukung desa wisata sebagai UKM imbas.

5. Memberdayakan masyarakat lokal dalam mempersiapkan diri menjadi pengelola home stay, yang memiliki keterampilan hospitality.

\section{METODE PELAKSANAAN}

Dalam perumusan program kerja ini kami mengacu pada hasil observasi yang telah dilaksanakan sehingga program yang akan dilaksanakan nantinya dapat disesuaikan dengan kebutuhan LPD (sesuai situasi dan kondisi). Rincian program kerja PKM Universitas Triatma Mulya terdiri dari:

1. Program Non Fisik

a. Pendampingan dan Pembekalan Prosedur Transaksi Tabungan.

b. Pendampingan dan Pembekalan Prosedur Permohonan Kredit \& Transaksi Kredit.

c. Pendampingan dan Pembekalan Prosedur Operasional Teller/Kasir.

d. Pendampingan dan Pembekalan Pembuatan Laporan Keuangan LPD.

2. Program Fisik

a. Pengadaan Filling Cabinet 4 susun/Laci dan Name Desk.

b. Pengadaan dan pemasangan Struktur Organisasi LPD Desa Adat Cepaka

\section{HASIL DAN PEMBAHASAN}

Berdasarkan tujuan dari pelaksanaan kegiatan PKM, terdapat beberapa program yang dapat direalisasikan pada LPD Desa Adat Cepaka dijelaskan pada Tabel 1 berikut: 
Tabel 1

A. NON FISIK

\begin{tabular}{|c|c|c|c|c|}
\hline No & $\begin{array}{c}\text { Program } \\
\text { Kerja }\end{array}$ & Kegiatan & Tindak Lanjut & Hasil \\
\hline \multirow[t]{4}{*}{1} & $\begin{array}{l}\text { Pendampingan } \\
\text { dan } \\
\text { pembekalan } \\
\text { prosedur } \\
\text { transaksi } \\
\text { tabungan }\end{array}$ & $\begin{array}{l}\text { Diskusi dan } \\
\text { memberikan masukan } \\
\text { mengenai } \\
\text { penganalisaan kredit }\end{array}$ & $\begin{array}{l}\text { Menyarankan agar } \\
\text { menggunakan indikator- } \\
\text { indikator (syarat) tertentu } \\
\text { dalam pemberian kredit. } \\
\text { Contohnya nasabah wajib } \\
\text { memiliki kemampuan } \\
\text { dalam pengembalian kredit } \\
\text { (memiliki usaha/pekerjaan) }\end{array}$ & $\begin{array}{l}\text { Pihak LPD menyetujui } \\
\text { bahwa diperlukannya } \\
\text { analisa terkait } \\
\text { pemberian kredit, dan } \\
\text { juga ditambah lagi } \\
\text { dilakukannya analisa } \\
\text { rekam jejak nasabah } \\
\text { melalui informasi dari } \\
\text { koperasi-koperasi di } \\
\text { Desa Cepaka apakah } \\
\text { nasabah tersebut } \\
\text { memiliki masalah } \\
\text { kredit macet di koperasi } \\
\text { tersebut atau tidak. }\end{array}$ \\
\hline & & $\begin{array}{l}\text { Diskusi dan } \\
\text { memberikan masukan } \\
\text { mengenai verifikasi } \\
\text { data calon debitur }\end{array}$ & $\begin{array}{l}\text { Menyarankan verifikasi } \\
\text { data melalui form } \\
\text { pengajuan kredit, KTP, KK } \\
\text { dan juga menyarankan } \\
\text { untuk mem-verifikasi } \\
\text { persetujuan suami-istri } \\
\text { dalam pemberian kredit } \\
\text { untuk menghindari } \\
\text { terjadinya miskomunikasi }\end{array}$ & 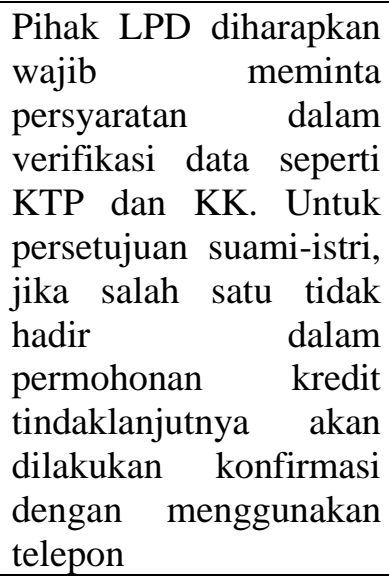 \\
\hline & & $\begin{array}{l}\text { Diskusi dan } \\
\text { memberikan masukan } \\
\text { mengenai keputusan } \\
\text { kredit }\end{array}$ & $\begin{array}{l}\text { Menyarankan agar semua } \\
\text { pihak yang terapat di } \\
\text { kepengurusan LPD untuk } \\
\text { terlibat dalam keputusan } \\
\text { pemberian kredit termasuk } \\
\text { Bendesa Adat }\end{array}$ & $\begin{array}{lc}\text { Fungsi controlling di } \\
\text { LPD diharapkan } \\
\text { menjadi lebih baik }\end{array}$ \\
\hline & & $\begin{array}{lr}\text { Diskusi } & \text { dan } \\
\text { memberikan masukan } \\
\text { mengenai pejanjian } \\
\text { kredit }\end{array}$ & $\begin{array}{l}\text { Menyarankan } \\
\text { mencantumkan antuk } \\
\text { pejaminan kredit untuk } \\
\text { mengelola risiko apabila } \\
\text { terjadi hal yang tidak } \\
\text { diinginkan seperti, } \\
\text { nasabah/debitur meninggal } \\
\text { dunia sebelum kredit lunas } \\
\text { dan peng-cover-an jika } \\
\text { suatu saat ada kredit macet. }\end{array}$ & $\begin{array}{l}\text { Untuk saat ini di LPD } \\
\text { Desa Adat Cepaka } \\
\text { keputusan mengenai } \\
\text { kebijakan dalam } \\
\text { menghadapi risiko } \\
\text { kredit macet, debitur } \\
\text { meninggal dunia, dsb. } \\
\text { dipegang oleh Bendesa } \\
\text { Adat selaku } \\
\text { penanggungjawab. }\end{array}$ \\
\hline
\end{tabular}




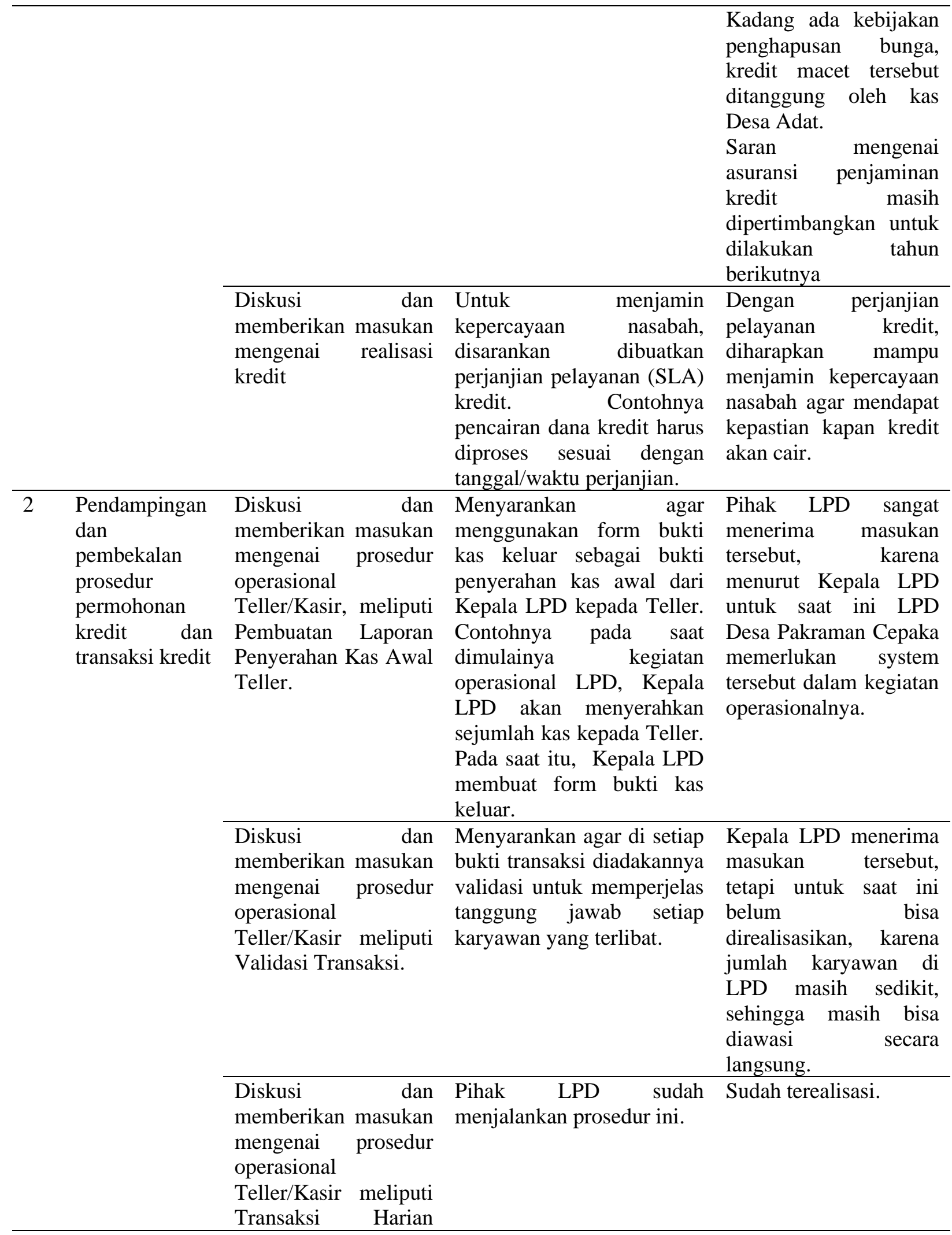


Teller.

\begin{tabular}{|c|c|c|}
\hline $\begin{array}{lr}\text { Diskusi } & \text { dan } \\
\text { memberikan } & \text { masukan } \\
\text { mengenai } & \text { prosedur } \\
\text { operasional } & \\
\text { Teller/Kasir } & \text { meliputi } \\
\text { Laporan } & \\
\text { Pengembalian } & \text { Kas } \\
\text { Akhir Teller. } & \end{array}$ & $\begin{array}{l}\text { Menyarankan } \\
\text { menggunakan form bukti } \\
\text { kas keluar sebagai bukti } \\
\text { pengembalian kas akhir } \\
\text { dari Teller LPD kepada } \\
\text { Kepala LPD. Contohnya } \\
\text { pada saat kegiatan } \\
\text { operasional LPD berakhir, } \\
\text { bagian Teller LPD akan } \\
\text { menyerahkan sejumlah kas } \\
\text { kepada Kepala LPD. Pada } \\
\text { saat itu, Teller mengisi } \\
\text { form bukti kas keluar } \\
\text { sebagai laporan } \\
\text { pengembalian kas akhir. }\end{array}$ & 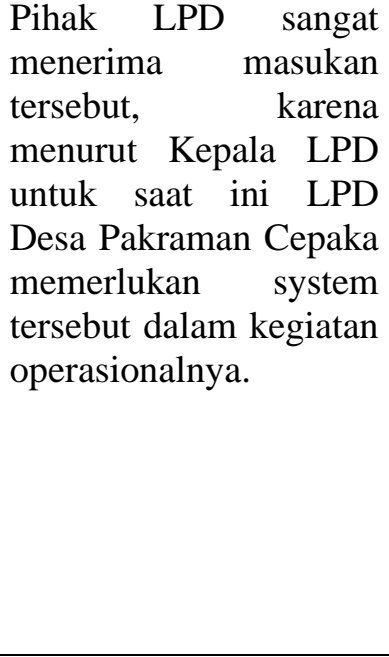 \\
\hline
\end{tabular}

Diskusi dan LPD Desa Pekraman Pihak LPD menerima

memberikan masukan Cepaka sudah menjalankan format yang kami mengenai prosedur prosedur ini dan kami berikan, sebagai operasional memberikan masukan referensi dalam Teller/Kasir meliputi format berita acara uang pembaharuan format Berita Acara Uang kas yang bisa dijadikan berita acara uang kas Kas. $\quad$ referensi. yang sudah ada sebelumnya.

\begin{tabular}{|c|c|c|c|c|}
\hline 3 & $\begin{array}{l}\text { Pendampingan } \\
\text { dan } \\
\text { pembekalan } \\
\text { prosedur } \\
\text { operasional } \\
\text { teller atau kasir }\end{array}$ & $\begin{array}{lr}\text { Diskusi } & \text { dan } \\
\text { memberikan } & \text { masukan } \\
\text { mengenai } & \text { prosedur } \\
\text { setoran } & \text { tabungan } \\
(\mathrm{BKM}) & \end{array}$ & $\begin{array}{l}\text { Memastikan agar jumlah } \\
\text { setoran tabungan nasabah } \\
\text { yang diterima kolektor } \\
\text { harus sama antara buku } \\
\text { tabungan dengan Laporan } \\
\text { transaksi harian kolektor }\end{array}$ & $\begin{array}{l}\text { Pihak LPD sudah } \\
\text { melakukan prosedur } \\
\text { tersebut }\end{array}$ \\
\hline & & $\begin{array}{l}\text { Diskusi dan } \\
\text { memberikan masukan } \\
\text { mengenai penarikan } \\
\text { Tabungan (BKK) }\end{array}$ & $\begin{array}{lr}\text { Menyarankan } & \text { petugas } \\
\text { kolektor untuk meminta } \\
\text { KTP nasabah dan meminta } \\
\text { nasabah } \\
\text { menandatangani } & \text { BKK } \\
\text { tersebut. Membawa buku } \\
\text { tabungan nasabah ke LPD } \\
\text { dan diserahkan ke teller } \\
\text { untuk diberikan stempel } \\
\end{array}$ & $\begin{array}{l}\text { Pihak LPD menerima } \\
\text { saran tersebut. } \\
\text { Penarikan tabungan } \\
\text { hanya bisa dilakukan di } \\
\text { LPD tidak dilapangan } \\
\text { karena kolektor tidak } \\
\text { membawa uang untuk } \\
\text { penarikan tabungan. }\end{array}$ \\
\hline & & $\begin{array}{l}\text { Diskusi dan } \\
\text { memberikan masukan } \\
\text { mengenai validasi } \\
\text { transaksi tabungan } \\
\text { dan data nasabah }\end{array}$ & $\begin{array}{l}\text { Menyarankan agar form } \\
\text { BKM dan BKK serta buku } \\
\text { tabungan diberi kode } \\
\text { validasi setiap karyawan } \\
\text { LPD agar mudah } \\
\text { melakukan controlling jika } \\
\text { terjadi ketidaksesuaian }\end{array}$ & $\begin{array}{l}\text { Pihak LPD menerima } \\
\text { saran tersebut tetapi } \\
\text { untuk saat ini kode } \\
\text { validasi belum ada } \\
\text { karena jumlah } \\
\text { karyawan di LPD } \\
\text { masih sangat terbatas } \\
\text { dan petugas kolektor }\end{array}$ \\
\hline
\end{tabular}


Vol 1, No 1, Juni 2021 hal. 21 - 30

(I Ketut Yudana $\mathrm{Adi}^{1}$, Kukuh Rian Setiawan ${ }^{2}$, Ida Ketut Kusumawijaya)

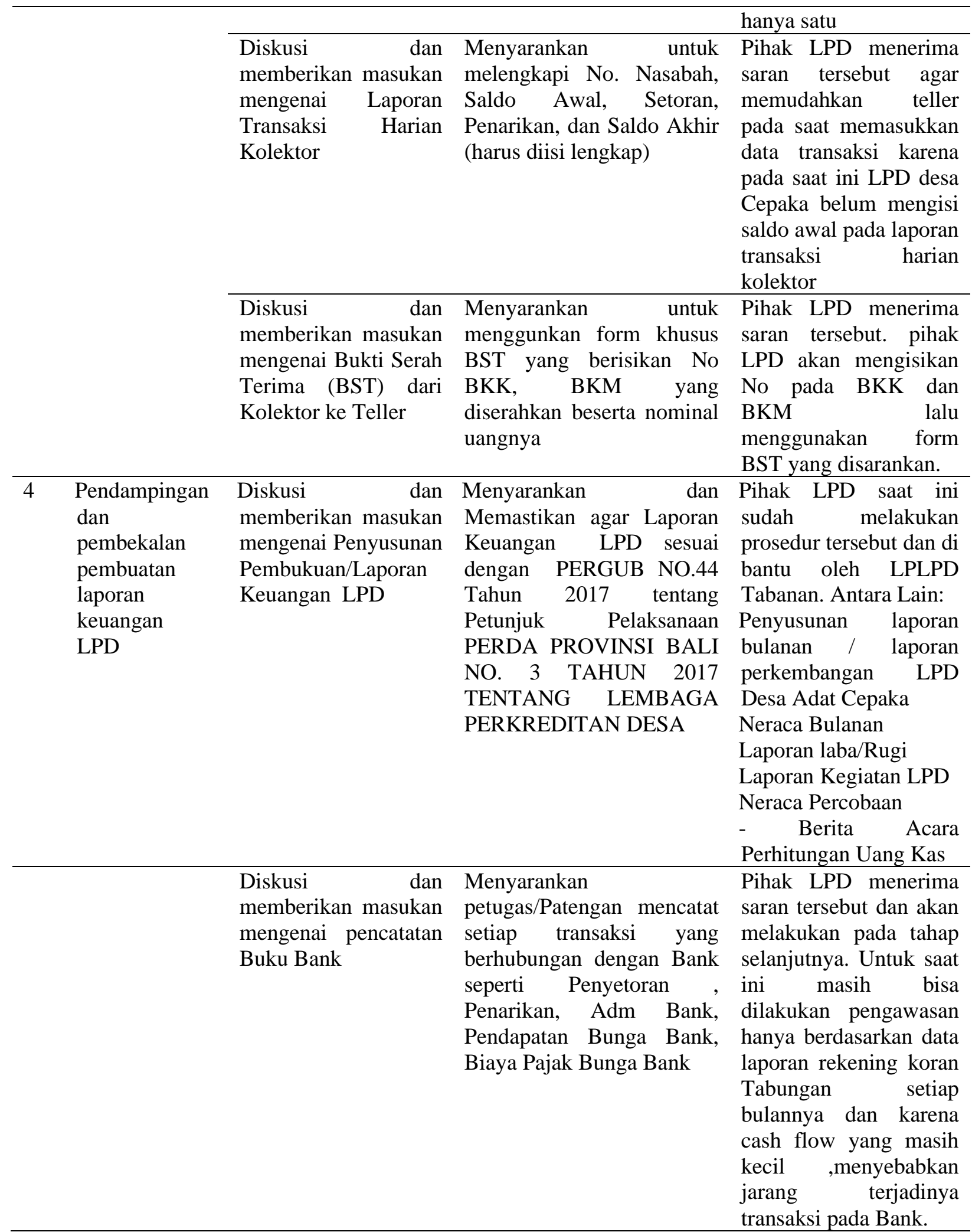


Vol 1, No 1, Juni 2021 hal. 21 - 30

(I Ketut Yudana $\mathrm{Adi}^{1}$, Kukuh Rian Setiawan ${ }^{2}$, Ida Ketut Kusumawijaya)

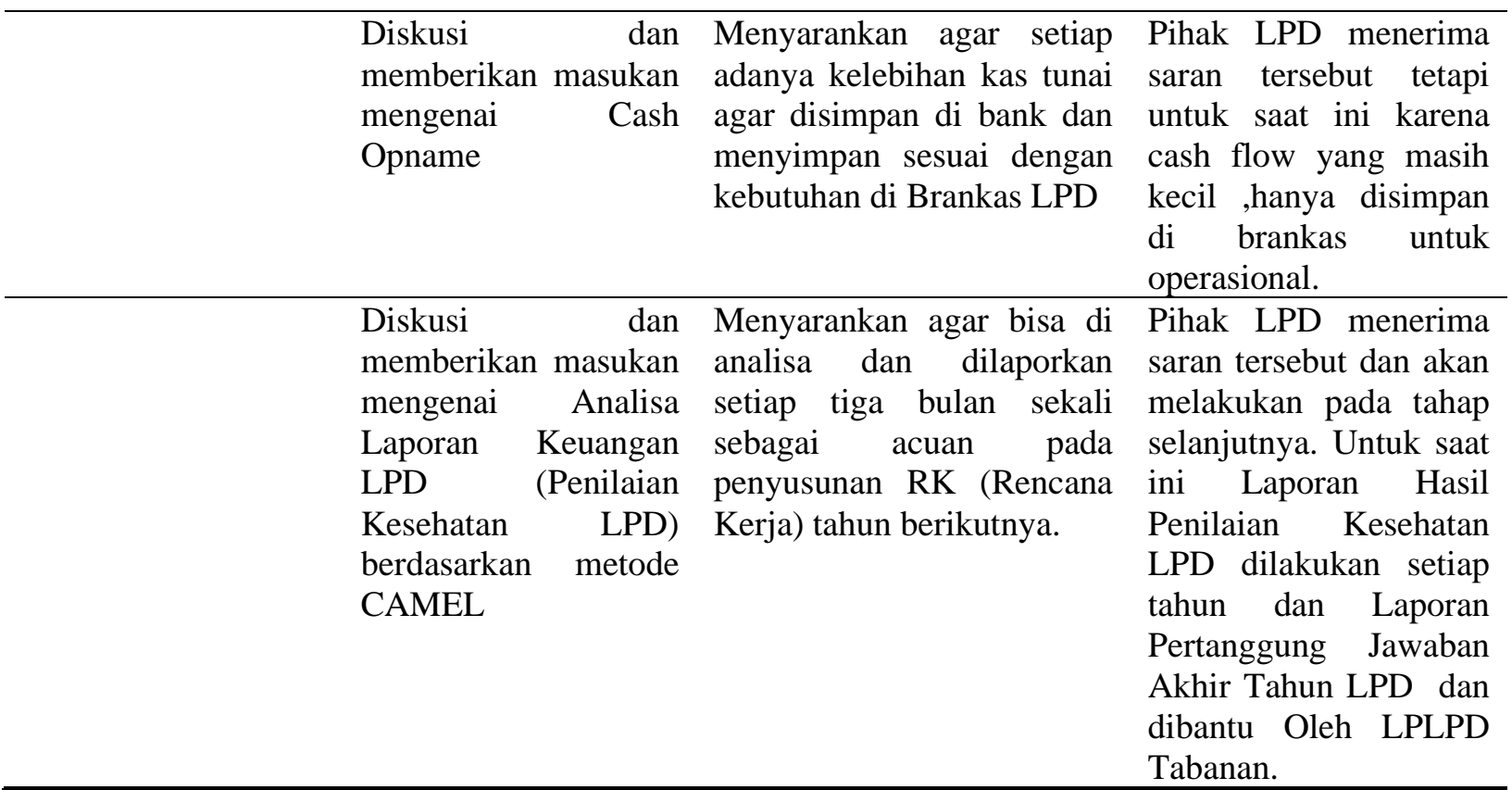

Tabel 2

Hasil Pelaksanaan Program Kerja LPD Desa AdatCepaka

B. FISIK

\begin{tabular}{|c|c|c|c|c|}
\hline No & $\begin{array}{c}\text { Program } \\
\text { Kerja }\end{array}$ & Kegiatan & Tindak Lanjut & Hasil \\
\hline \multirow[t]{2}{*}{1} & $\begin{array}{l}\text { Pengadaan } \\
\text { Filling Cabinet } \\
\text { dan name desk }\end{array}$ & $\begin{array}{l}\text { Pengadaan } \\
\text { Cabinet }\end{array}$ & $\begin{array}{l}\text { Memberikan } \\
\text { berupa Filling Cabinet di } \\
\text { Ruangan LPD Desa Adat } \\
\text { Cepaka untuk tempat } \\
\text { penyimpanan arsip file agar } \\
\text { tersusun rapi sehingga } \\
\text { pengamanan serta } \\
\text { pemeliharaan dokumen } \\
\text { terjaga dan terhindar dari } \\
\text { kerusakan yang disebabkan } \\
\text { oleh factor luar seperti } \\
\text { kebakaran atau serangga. }\end{array}$ & $\begin{array}{l}\text { Pihak LPD menerima } \\
\text { bantuan tersebut untuk } \\
\text { digunakan menyimpan } \\
\text { dokumen penting. }\end{array}$ \\
\hline & & $\begin{array}{l}\text { Pengadaan Name } \\
\text { Desk (Papan Nama } \\
\text { Meja) }\end{array}$ & $\begin{array}{l}\text { Memberikan bantuan } \\
\text { berupa Name Desk sebagai } \\
\text { petunjuk identitas setiap } \\
\text { karyawan LPD di masing - } \\
\text { masing bagian agar } \\
\text { mempermudah r dan } \\
\text { memperlancar pelayanan } \\
\text { nasabah. }\end{array}$ & $\begin{array}{lr}\text { Pihak LPD menerima } \\
\text { bantuan tersebut untuk } \\
\text { digunakan sebagai } \\
\text { petunjuk identitas } \\
\text { setiap karyawan LPD. }\end{array}$ \\
\hline 2 & $\begin{array}{l}\text { Pengadaan } \\
\text { struktur } \\
\text { organisasi LPD }\end{array}$ & $\begin{array}{l}\text { Pengadaan struktur } \\
\text { organisasi LPD }\end{array}$ & 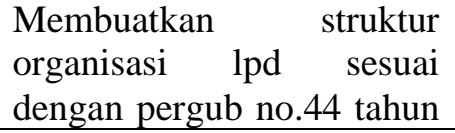 & $\begin{array}{l}\text { Struktur Organisasi } \\
\text { baru telah terpasang } \\
\text { menggantikan papan }\end{array}$ \\
\hline
\end{tabular}


SAVE: Synergy and Society Service

Vol 1, No 1, Juni 2021 hal. 21 - 30

(I Ketut Yudana Adi ${ }^{1}$, Kukuh Rian Setiawan ${ }^{2}$, Ida Ketut Kusumawijaya)

dan tempat
sampah
2017 tentang petunjuk struktur yang lama pelaksanaan perda provinsi

bali no. 3 tahun 2017

tentang lembaga

perkreditan desa

Kegiatan PKM yang merealisasikannya bersama

dilakukan guna membantu stakeholder sehingga dapat berjalan pengelolaan keuangan LPD Desa dengan lancar, pendampingan Adat Cepaka dimulai dari program pengelolaan keuangan diharapkan kerja non fisik dan juga program kerja dapat memberikan dampak positif fisik dengan tujuan melakukan bagi warga Desa Adat Cepaka pendampingan secara langsung sehingga kedepannya dapat dengan cara mengobservasi terlebih mengelola keuangannya secara dahulu pokok permasalahan, mandiri dengan lebih baik. menentukan program kerja dan
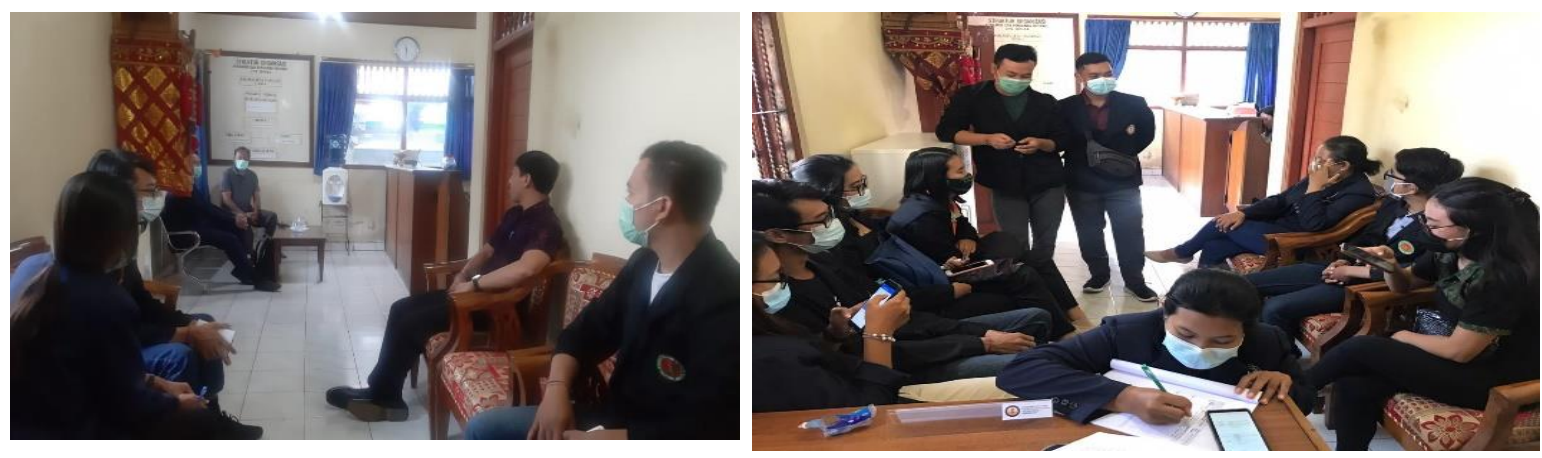

Gambar 1

Kordinasi Penyusunan Program Kerja
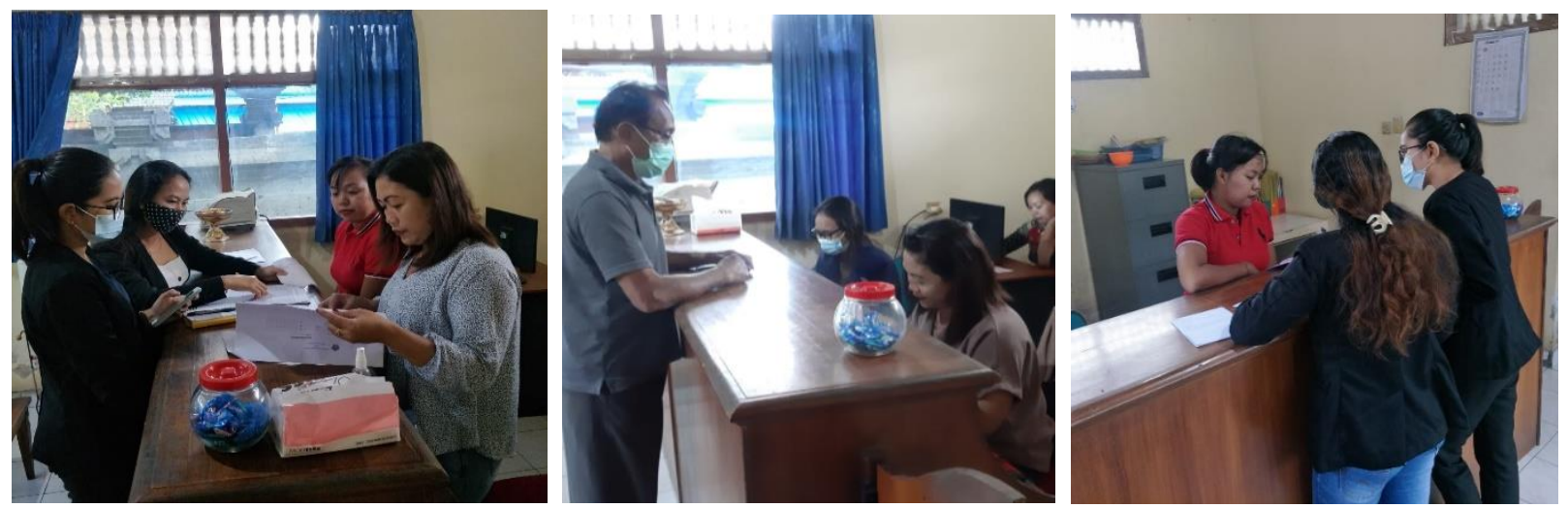

Gambar 2

Pelatihan dan Pendampingan Pembukuan 

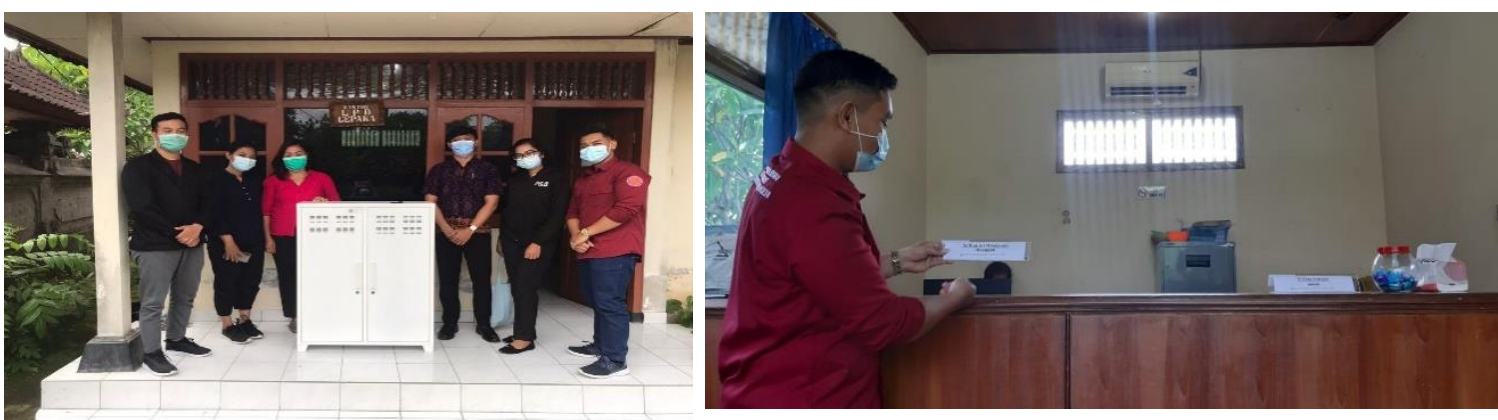

Gambar 3

Bantuan Program Kerja Fisik

\section{KESIMPULAN}

Berdasarkan hasil pelaksanaan PKM di LPD Desa Adat Cepaka dapat disimpulkan sebagai berikut :

1. Telah terbentuk pemahaman dari para pengurus LPD Desa Adat Cepaka tentang proses pembukuan dan pengelolaan keuangan secara benar seperti laporan harian, bulanan dan laporan laba rugi.

2. Telah diberikan pemahaman kepada Pengurus LPD Desa Adat Cepaka pentingnya pembagian tugas dan tanggung jawab antara bagian administrasi dan bagian lapangan.

3. Telah terbentuk mindset positif SDM selaku pengelola menerapkan strategi pemasaran dan berinovasi dengan produkproduk unggulan yang sesuai dengan kebutuhan nasabahnya.

\section{UCAPAN TERIMA KASIH}

Kegiatan PKM ini tidak akan dapat terlaksana tanpa bantuan dan dukungan dari berbagai pihak, oleh sebab itu dalam kesempatan ini kami mengucapkan terimakasih yang sebesar-besarnya kepada LP3M Universitas Triatma Mulya, Dekan Fakultas Bisnis dan Sosial Humaniora Universitas Triatma Mulya, Kepala Desa Cepaka, serta pihak-pihak yang tidak dapat disebutkan satu persatu.

\section{DAFTAR PUSTAKA}

Gubernur Bali. (2017). Peraturan Daerah Provinsi Bali Nomor 3 Tahun 2017. Tentang Lembaga Perkreditan Desa (LPD) Disertai Keputusan Gubernur Bali. Denpasar. Biro Prekonomian dan Pembangunan Sekretariat Daerah Provinsi Bali.

(2017). Peraturan

Gubernur Nomor 44 Tahun 2017. Tentang petunjuk pelaksanaan Perda Provinsi Bali No.3 tahun 2017 Tentang Lembaga Perkreditan Desa Disertai Keputusan Gubernur Bali. Denpasar. Biro Prekonomian dan Pembangunan Sekretariat Daerah Provinsi Bali. 